\title{
Detecção molecular de Neospora caninum em macaco-da-noite (Aotus azarae) de vida livre no estado do Mato Grosso: relato de caso
}

\author{
[Molecular detection of Neospora caninum in azara's night monkey (Aotus azarae) of \\ wildlife in the state of Mato Grosso: Case report] \\ T.L.C. Costa $^{1}$, G.A. Iglesias ${ }^{1}$, J.M.A. Rosa ${ }^{2}$, H.J. Bento ${ }^{1}$, L.A.S. Rondelli ${ }^{2}$, F. Furlan ${ }^{2}$, T.O. Morgado ${ }^{1}$, \\ V. Dutra ${ }^{2}$, S.H.R. Corrêa ${ }^{1}$. \\ ${ }^{1}$ Hospital Veterinário - Faculdade de Medicina Veterinária - Universidade Federal de Mato Grosso \\ (FAVET-UFMT) - Cuiabá, MT \\ ${ }^{2}$ Faculdade de Medicina Veterinária - Universidade Federal de Mato Grosso \\ (FAVET-UFMT) - Cuiabá, MT
}

\begin{abstract}
RESUMO
Estudos indicam, por meio de infecção experimental, que primatas não humanos são susceptíveis à infecção por Neospora caninum. Relata-se um caso de um macaco-da-noite (Aotus azarae infulatus), que apresentou sinais inespecíficos e não respondeu à terapêutica clínica de suporte, evoluindo a óbito, encaminhado em seguida para exame anatomopatológico. Amostras de tecidos foram coletadas e processadas rotineiramente para confecção de lâminas histológicas. Microscopicamente, a principal lesão foi observada no coração e consistia em miocardite necrótica multifocal por protozoário, com a presença de estruturas compatíveis com o estágio de taquizoítos de protozoários dos gêneros Neospora sp. ou Toxoplasma sp. No sistema nervoso central, predominantemente no tronco encefálico, havia estruturas semelhantes às descritas no coração. Os resultados da reação em cadeia pela polimerase (PCR) foram positivos para $N$. caninum e negativos para Toxoplasma gondii, usando DNA extraído do sangue e dos tecidos. Este relato de caso fornece evidências histológicas e moleculares de que o primata em questão foi susceptível a uma infecção natural, porém estudos devem ser realizados para investigar o real papel dos primatas no ciclo de vida de $N$. caninum.
\end{abstract}

Palavras-chave: primatas, sarcocystidae, biologia molecular, neosporose

\begin{abstract}
Studies indicate through experimental infection that non-human primates are susceptible to infection by Neospora caninum. This report is of a case of a night monkey (Aotus azarae infulatus) that presented nonspecific signs and did not respond to supportive clinical therapy evolving to death, followed by a pathology examination. Tissue specimens were routinely collected and processed for the preparation of histological slides. Microscopically, the main lesion was observed in the heart and consisted of multifocal necrotic myocarditis by protozoa, with the presence of structures compatible with the stage of protozoan tachyzoites of the genus Neospora sp. or Toxoplasma sp. In the central nervous system, predominantly in the brainstem there were structures similar to those described in the heart. Polymerase chain reaction $(P C R)$ results were positive for $\mathrm{N}$. caninum and was negative for Toxoplasma gondii using DNA extracted from blood and tissues. This case report provides histological and molecular evidence that the primate in question was susceptible to a natural infection, but studies should be conducted to investigate the real role of primates in the life cycle of $\mathrm{N}$. caninum.
\end{abstract}

Keywords: primates, sarcocystidae, molecular biology, neosporosis

Recebido em 17 de março de 2017

Aceito em 10 de julho de 2017

E-mail: tania.lcc@hotmail.com 


\section{INTRODUÇÃO}

Neospora caninum é um protozoário intracelular obrigatório, pertencente ao filo Apicomplexa, classe Sporozoa, ordem Eucoccidiida e família Sarcocystidae, estreitamente relacionado com Toxoplasma gondii em razão da proximidade filogenética e da formação de cistos (Dubey, 2003; Dubey e Lindsay, 1996).

A neosporose é uma importante causa infecciosa de aborto, natimorto ou morte perinatal em bovinos e doença neuromuscular em cães, também reportada em outras espécies de animais domésticos e selvagens (Donahoe et. al., 2015). Possui um ciclo heteróxeno com três formas de desenvolvimento: os taquizoítos, os cistos contendo bradizoítos e os oocistos. Os taquizoítos podem ser encontrados em várias células, como hepatócitos, células epiteliais renais, células do endotélio vascular, miócitos, macrófagos, fibroblastos e células nervosas. Os cistos teciduais são observados primariamente no sistema nervoso central e os oocistos são as formas infectantes, excretados exclusivamente nas fezes dos hospedeiros definitivos, os quais esporulam no ambiente (Dubey e Lindsay, 1996).

Os hospedeiros definitivos já identificados são os cães (Canis lupus familiaris), os coiotes ( $C$. latrans), os dingos (C. lupus dingo) e os lobos cinzentos (C. lupus lupus). Diversas espécies podem atuar como hospedeiros intermediários. Animais carnívoros provavelmente se infectam por ingestão de tecido contendo os cistos, e os herbívoros pela ingestão de alimentos ou água contaminados com oocistos esporulados. A transmissão transplacentária pode ocorrer quando taquizoítos atravessam a barreira placentária (Donahoe et al., 2015; Dubey, 2003; Dubey e Lindsay, 1996).

Ainda que o potencial zoonótico desse parasito seja discutível, estudos realizados por meio de avaliação sorológica em seres humanos indicam a exposição ou infecção de indivíduos portadores do vírus HIV ou com transtornos neurológicos por N. caninum (Lobato et al., 2006). A suscetibilidade de primatas não humanos foi confirmada com a infecção experimental de macacos Rhesus (Macaca mulatta) (Barr et al., 1994).
Atualmente, o diagnóstico da neosporose foi aprimorado pelo desenvolvimento de testes pela técnica da reação em cadeia pela polimerase (PCR), que permitem uma identificação rápida, altamente sensível e específica por meio da amplificação dos fragmentos de DNA do parasito (Donahoe et al., 2015). No presente estudo, relata-se a primeira evidência molecular de infecção por $N$. caninum em um macaco da noite (Aotus azarae infulatus), proveniente do município de Cuiabá, estado do Mato Grosso, região Centro-Oeste do Brasil.

\section{CASUÍSTICA}

Um macaco-da-noite (Aotus azarae infulatus), fêmea, jovem, 944g, de vida livre, encontrado no perímetro urbano do município de Cuiabá, estado de Mato Grosso, Brasil, foi atendido no Hospital Veterinário da Universidade Federal de Mato Grosso (Hovet-UFMT). O animal chegou letárgico, anoréxico e desidratado. Durante o período de internação, ele foi contido fisicamente com luvas de raspa de couro para coleta de sangue por venipunção da veia jugular, sendo o sangue coletado acondicionado em microtubo para pesquisa de patógenos por meio de testes moleculares. Foi realizado tratamento suporte com fluidoterapia (ringer com lactato) via endovenosa, antibioticoterapia com sulfadoxina na dose de $30 \mathrm{mg} / \mathrm{kg}$ via intramuscular, hepatoprotetor à base de ornitina, citrulina e arginina via endovenosa na dose de $1 \mathrm{ml} / \mathrm{kg}$, dipirona na dose de $25 \mathrm{mg} / \mathrm{kg}$ via oral, levamisol na dose de $7,5 \mathrm{mg} / \mathrm{kg}$ e suplementação vitamínica; a resposta ao tratamento suporte foi insatisfatória, evoluindo a óbito após sete dias.

O animal foi enviado ao Laboratório de Patologia Veterinária do Hovet-UFMT para exame anatomopatológico. Ao exame macroscópico, verificou-se fígado aumentado de tamanho, com coloração amarelada e consistência friável. Nos demais órgãos, não havia alterações macroscópicas significativas. Amostras de tecidos foram coletadas e fixadas em formol tamponado a $10 \%$ e processadas rotineiramente para confecção de lâminas histológicas. Cortes de 3 a $5 \mu \mathrm{m}$ foram obtidos em micrótomo rotativo e corados com hematoxilina-eosina (HE). Microscopicamente, observou-se no coração, miocardite necrótica multifocal por protozoário, caracterizada por segmentação e eosinofilia do sarcoplasma de 
miofibras acompanhado de infiltrado linfoplasmocitário associado a estruturas com tamanho variando de 4 a $6 \mu \mathrm{m}$, em formato ovoide com uma extremidade arredondada e outra afilada, núcleo basofílico em formato de "lua crescente", citoplasma eosinofílico compatível com o estágio de taquizoítos de protozoários dos gêneros Neospora sp. ou Toxoplasma sp. (Fig.1A). No sistema nervoso central, predominantemente no tronco encefálico, notavam-se nódulos gliais com distribuição multifocal, observando-se no interior estruturas semelhantes às descritas no coração (Fig. 1B). Adicionalmente, no fígado havia vacuolização acentuada difusa no citoplasma de hepatócitos, sendo esses vacúolos únicos, ocupando a maior parte do citoplasma dos hepatócitos, deslocando e comprimindo seus núcleos lateralmente. Os rins apresentavam infiltrado linfoplasmocitário multifocal moderado no interstício $\mathrm{e}$ pericapsular, e o pulmão apresentava infiltrado linfoplasmocitário focal leve e congestão focal leve.

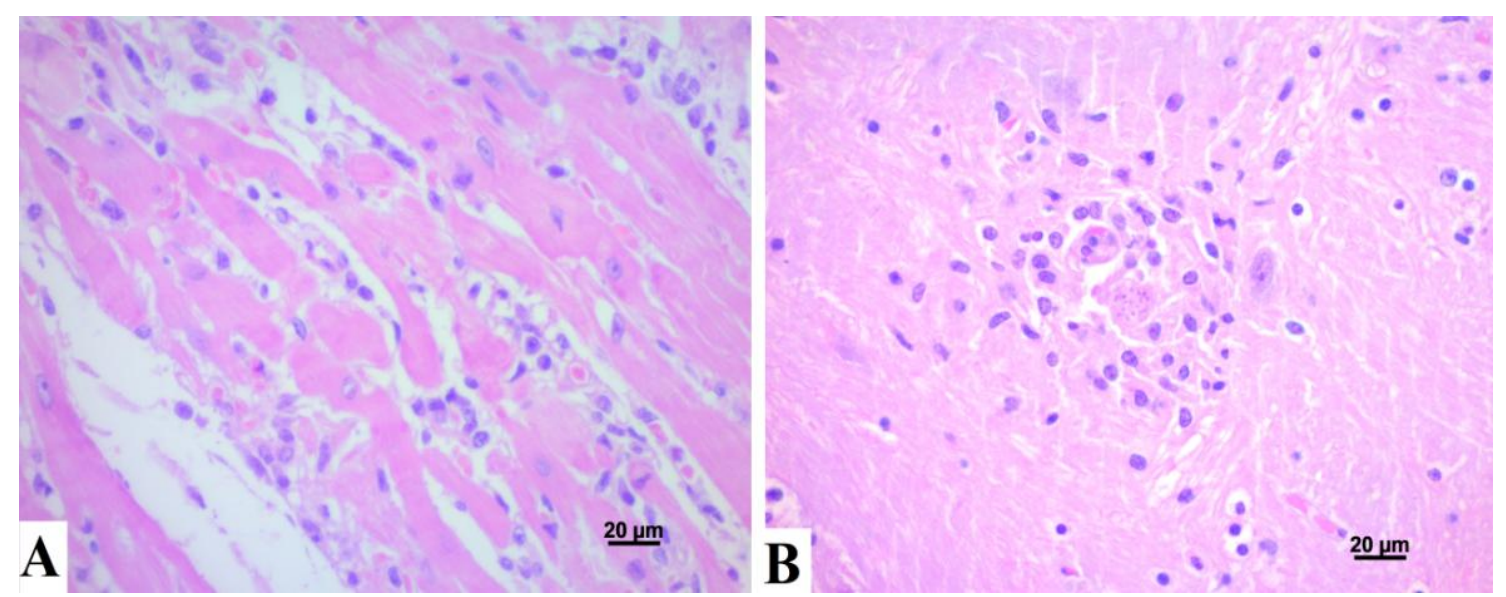

Figura 1. Coração (A): evidencia-se necrose multifocal de miofibras associada a infiltrado moderado linfoistioplasmocitário. Encéfalo em região de tálamo (B): nódulo glial em substância branca com área central contendo taquizoítos de Neospora sp. Obj. 40x.

Amostras de tecidos de encéfalo, pulmão, fígado e rim foram recolhidos assepticamente e congelados a $-20^{\circ} \mathrm{C}$ até serem utilizados para estudos moleculares. A extração do DNA da amostra de sangue total e tecidos foi realizada com base na técnica de fenol-clorofórmio descrita por Sambrook e Russell (2001).

Para realizar a PCR para $T$. gondii, utilizaram-se os oligonucleotídeos universais 694-714 (5, GGAACTGCATCCGTTCATGAG 3') e 887868 (5' TCTTTAAAGCGTTCGTGGTC 3'), que resultam no produto de amplificação de 194 pares de base (pb) do gene B1, região conservada do genoma de $T$. gondii altamente específico para este protozoário, apresentando uma repetição de 35 cópias dentro do genoma (Burg et al., 1989). Para a amplificação, foi utilizada uma reação com volume final de $25 \mu \mathrm{L}$, contendo 0,8 pmol de cada primer, $2,7 \mathrm{mM}$ de $\mathrm{MgCl} 2,1 \mathrm{x}$ Tampão PCR 10x (200mM Tris-HCl pH8.4, $500 \mathrm{mM} \mathrm{KCl}), 0,2 \mathrm{mM}$ de DNTPs, $1 \mathrm{U}$ de Taq DNA polimerase e 10ng do DNA testado. A reação foi realizada em termociclador (BIORAD MyCyclerThermalCycler), nas seguintes condições: desnaturação inicial a $95^{\circ} \mathrm{C}$ por cinco minutos; 30 ciclos de 30 segundos a $95^{\circ} \mathrm{C}$, anelamento dos oligonucleotídeos a $47^{\circ} \mathrm{C}$ por 45 segundos, extensão por dois minutos a $72^{\circ} \mathrm{C}$; e uma extensão final de cinco minutos a $72^{\circ} \mathrm{C}$. $\mathrm{O}$ produto de amplificação, corado com GelRedTm (Nucleic Acid gel stain, Biotium), foi fracionado por eletroforese em gel de agarose $(2,0 \%)$ e analisado em sistema de fotodocumentação ChemiDocTm XRS+(Bio-Rad). Para o controle negativo, foi utilizada água ultrapura, e para o controle positivo, foram utilizados 50ng de DNA genômico a partir de cultivo celular do parasito.

A técnica de Nested-PCR para identificação de $N$. caninum foi realizada com os oligonucleotídeos NN1 (5'TCAACCTTTGAATCCCAA-3), NN2 (5'CGAGCCAAGACATCCATT-3'), NP1 (5'TACTACTCCCTGTGAGTTG-3') e NP2 (5'- 
TCTCTTCCCTCAAACGCT-3) descritos por Buxton et al. (1998), que amplificam um produto de 213pb da região 1TS-1 (Internal Transcribed Spacer) do rRNA de $N$. caninum. A reação foi realizada em um volume final de $25 \mu \mathrm{L}$, contendo $1,5 \mathrm{mM}$ de $\mathrm{MgCl} 2$, 1x Tampão PCR 10x (200mM Tris- $\mathrm{HCl} \mathrm{pH} 8.4,500 \mathrm{mM} \mathrm{KCl}), 0,2 \mathrm{mM}$ de dNTPs e $1 \mathrm{U}$ de Taq DNA polimerase (Taq DNA Polymerase from Thermus aquaticus, Sigma-Aldrich $^{\circledR}$, USA) em termociclador My CyclerTM thermal cycler (Bio-Rad), nas seguintes condições: desnaturação inicial a $94^{\circ} \mathrm{C}$ por quatro minutos seguida por 26 ciclos de dois minutos a $94^{\circ} \mathrm{C}$, anelamento a $50^{\circ} \mathrm{C}$ por dois minutos, extensão por dois minutos a $72^{\circ} \mathrm{C}$; e uma extensão final de cinco minutos a $72^{\circ} \mathrm{C}$. Para a reação primária, foi utilizado $0,16 \mathrm{pmol}$ de cada oligonucleotideo (NN1 e NN2) e 10ng de DNA. Para a reação secundária, utilizou-se $0,16 \mathrm{pmol}$ dos oligonucleotideos NP1 e NP2 e uma alíquota de $1,0 \mu \mathrm{L}$ do produto de amplificação da reação primária. $\mathrm{O}$ controle positivo utilizado foi DNA de cultivo celular do parasito previamente identificado. Os produtos de amplificação, corados com GelRedTm (Nucleic Acid gel stain, Biotium), foram fracionados por eletroforese em gel de agarose $(2 \%)$ e analisados em sistema de fotodocumentação ChemiDocTm XRS+ (BioRad), com auxílio do software Image LabTm (Bio-Rad). O marcador de massa molecular utilizado foi Ladder 100pb (GeneRuler 100pb DNA Ladder, Thermo Scientific).

$\mathrm{Na}$ Nested-PCR para $N$. caninum, obteve-se resultado positivo no sangue, encéfalo, pulmão, rim e fígado, visualizando-se um fragmento de $213 \mathrm{pb}$, enquanto na PCR das amostras de sangue e tecidos para $T$. gondii os resultados foram negativos.

Para o sequenciamento do amplicon, foi utilizado o sequenciador ABI-PRISM 3500 Genetic Analyzer, e a sequência nucleotídica foi submetida ao GenBank usando o programa BLASTn

(http://www.ncbi.nlm.nih.gov/blast/Blast.cgi) para identificação do microrganismo, obtendo-se 99\% de identidade com a sequência do $N$. caninum (número de acesso no GenBank: KY659810).

\section{DISCUSSÃO}

Existem estudos acerca do papel de diversas espécies selvagens no ciclo de vida do $N$. caninum. Com relação aos primatas não humanos, as informações são limitadas quanto à ocorrência e à importância da infecção pelo protozoário, no entanto a suscetibilidade desses animais à neosporose foi confirmada por meio de infecção experimental de macacos Rhesus (Macaca mulatta) (Ho et al., 1997).

$\mathrm{Na}$ avaliação microscópica do caso, o coração apresentou necrose moderada e multifocal de miofibra, acompanhada de infiltrado linfoplasmocitário. $N$. caninum é capaz de produzir lesões necróticas claramente visíveis em poucos dias e causa a morte celular pela multiplicação ativa de taquizoítos (Dubey e Lindsay, 1996). Estruturas compatíveis com taquizoítos foram observadas entremeando as miofibras do coração e no sistema nervoso central, descritos como estruturas em formato levemente ovoide, com uma extremidade arredondada e outra afilada e com tamanho variando de 4 a $6 \mu \mathrm{m}$. É descrito que os taquizoítos apresentam forma ovoide, semilunar ou globular e medem de 3 a 7 x 1 a $5 \mu \mathrm{m}$, dependendo do estágio de divisão (Dubey e Lindsay, 1996). Um diagnóstico presuntivo de infecção por protozoário pode ser feito com base em lesões histológicas características, porém tem uma baixa sensibilidade, devendo ser realizado em conjunto com outros testes diagnósticos disponíveis (Donahoe et al., 2015).

Williams et al. (2002) descreveram um caso em um filhote de rinoceronte branco (Ceratotherium simum) com lesões similares ao caso em questão, como a miocardite difusa e alterações hepáticas. O tecido miocárdico desse filhote revelou taquizoítos intracelulares e bradizoítos encistados, com as características ultraestruturais consistentes com as descritas para $N$. caninum. Em estudos realizados por Toscan et al. (2012), por meio da inoculação de $N$. caninum em gerbils (Meriones unguiculatus), observou-se que, na fase aguda, os animais apresentaram fígado aumentado na avaliação macroscópica durante a necropsia, além da detecção do DNA do agente em diferentes tecidos, como encéfalo, pulmão, rim e fígado, sendo esses achados compatíveis com o presente caso. 
No experimento com macacos Rhesus ( $M$. mulata), os fetos infectados apresentaram diferentes lesões no sistema nervoso central, como encefalite multifocal leve e meningoencefalite necrosante multifocal; em ambos os casos, os taquizoítos de Neospora foram detectados em associação com as lesões teciduais (Barr et al., 1994). As lesões descritas no coração e no sistema nervoso do macaco-danoite (A. a. infulatus) estavam associadas com as estruturas compatíveis com o estágio de taquizoítos de protozoários do gênero Neospora sp. ou Toxoplasma sp.

A técnica de PCR apresenta alta sensibilidade e especificidade para detecção do DNA de $N$. caninum, sendo o cérebro o tecido de eleição na pesquisa desse agente em animais selvagens. (Donahoe et al., 2015; Dubey, 2003). No presente relato, a técnica molecular foi realizada a partir de sangue e tecidos diversos (encéfalo, pulmão, rim e fígado), sendo detectada a presença do DNA em todas as amostras avaliadas. Ho et al. (1997) relataram a detecção de $N$. caninum em sangue e tecidos, incluindo encéfalo, pulmão, rim e fígado de macacos Rhesus (Macaca mulatta) infectados experimentalmente, sendo esses achados compatíveis com o presente relato. A análise de tecidos múltiplos aumenta a sensibilidade da detecção de $N$. caninum, além da pouca informação acerca da distribuição tissular do parasito na vida selvagem, tornando-se necessário amostrar múltiplos tecidos a fim de evitar a subestimação da infecção (Donahoe et al., 2015).

De acordo com Prates e Bicca-Marques (2005), coprofagia é um hábito observado em primatas não humanos. Os oocistos, que são a forma infectante, são excretados exclusivamente nas fezes dos hospedeiros definitivos (Dubey e Lindsay, 1996). O animal em questão foi encontrado em perímetro urbano, tendo fácil acesso a fezes de cães (C. lupus familiaris), que são identificados como hospedeiro definitivo de $N$. caninum, sendo a ingestão de água ou alimentos contaminados com os oocistos esporulados uma forma de infecção. Em um estudo retrospectivo realizado com 199 cães atendidos no Hospital Veterinário na
Universidade de Cuiabá, localizado no município de Cuiabá, Igarashi et al. (2015) demonstraram que $15,6 \%$ dos cães apresentaram anticorpos anti-N. caninum.

Devido à semelhança dos taquizoítos ao microscópio óptico e à estreita relação filogenética de $N$. caninum e T. gondii (Dubey e Lindsay, 1996; Dubey, 2003), é importante que se realize o diagnóstico diferencial entre esses dois parasitos. Além disso, a toxoplasmose é uma das principais doenças nos primatas do Novo Mundo, sendo considerada uma doença fatal nesses animais (Andrade et al., 2007). Primatas não humanos infectados via transplacentária por $N$. caninum apresentam lesões semelhantes à toxoplasmose (Barr et al., 1994), reforçando, assim, a gravidade da neosporose nesses animais e a importância do diagnóstico diferencial.

\section{CONCLUSÃO}

Foi demonstrado que $N$. caninum pode estar presente em primatas neotropicais. Os impactos epidemiológicos e a ocorrência da doença em primatas não humanos permanecem mal compreendidas, devendo ser realizados estudos que mensurem a susceptibilidade real e as taxas de infecção de neosporose nesses animais.

\section{REFERÊNCIAS}

ANDRADE, M.C.R.; COELHO, J.M.C.O.; AMENDOEIRA, M.R.R. et al. Toxoplasmosis in squirrel monkeys: histological and immunohistochemical analysis. Cienc. Rural, v.37, p.1724-1727, 2007.

BARR, B.C.; CONRAD, P.A.; SVERLOW, K.W. et al. Experimental fetal and transplacental Neospora infection in the nonhuman primate. Lab. Investig., v.71, p.236-242, 1994.

BURG, J.L.; GROVER, C.M.; POULETTY, P.; BOOTHROYD, J.C. Direct and sensitive detection of a pathogenic protozoan, toxoplasma gondii, by polymerase chain reaction. J. Clin. Microbiol., v.27, p.1787-1792, 1989.

BUXTON, D.; MALEY, S.W.; WRIGHT, S. et al. The pathogenesis of experimental neosporosis in pregnant sheep. J. Comp. Pathol., v.118, p.267-279, 1998. 
DONAHOE, S.L.; LINDSAY, S.A.; KROCKENBERGER, M. et al. A review of neosporosis and pathologic findings of Neospora caninum infection in wildlife. Int. J. Parasitol. Parasites Wildl., v.4, p.216-238, 2015.

DUBEY, J.P. Review of Neospora caninum and neosporosis in animals. Korean J. Parasitol., v.41, p.1-16, 2003.

DUBEY, J.P.; LINDSAY, D.S. A review of Neospora caninum and neosporosis. Vet. Parasitol., v.67, p.1-59, 1996.

HO, M.S.Y.; BARR, B.C.; TARANTAL, A.F. et al. Detection of Neospora from tissues of experimentally infected Rhesus Macaques by PCR and specific DNA probe hybridization. $J$. Clin. Microbiol., v.35, p.1740-1745, 1997.

IGARASHI, M.; SANTOS, L.A.; AMUDE, A.M. et al. Ocorrência de anticorpos antineospora caninum e estudo dos fatores de risco em cães de Cuiabá e Várzea Grande-MT, atendidos em hospital veterinário. Vet. Zootec., v.22, p.619-624, 2015.
LOBATO, J.; SILVA, D.A.O.; MINEO, T.W.P. et al. Detection of immunoglobulin $\mathrm{G}$ antibodies to Neospora caninum in humans: High seropositivity rates in patients who are infected by Human Immunodeficiency Virus or have neurological disorders. Clinical and Vaccine Immunology, v.13, p. 84-89, 2006.

PRATES, H.M.; BICCA-MARQUES, J.C. Coprophagy in captive brown capuchin monkeys (Cebus apella). Neotropical primates, v.13, p.1821, 2005.

SAMBROOK, J.; RUSSELL, D. Molecular cloning: a laboratory manual. New York: Cold Spring Habor Laboratory Press, 2001. 2100p.

TOSCAN, G.; CAMILLO, G.; WEBER, A. et al. Detecção de ácidos nucleicos em tecidos de gerbils submetidos à infecção aguda por Neospora caninum. Cienc. Rural, v.42, p.18651871, 2012.

WILLIAMS, J.H.; ESPIE, I.; WILPE, E.V. et al. Neosporosis in a white rhinoceros (Ceratotherium simum) calf. J. S. Afr. Vet. Assoc., v.73, p.38-43, 2002. 